PATHOLOGICAL PHYSIOLOGY AND CLINICAL DESCRIPTION OF THE ANÆMIAS.

By William Bosworth Castle and George Richard Minot. (Edited by Henry A. Christian). Oxford Medical Publications. 1936. Price 15/-.

This volume, which is reprinted from the Oxford Loose-Leaf System of Medicine, will be welcomed in this handy form by all who are interested in diseases of the blood. It represents probably the most comprehensive and judicial survey of the subject, dealing as it does with both the experimental and clinical aspects of the problem of physiological and pathological hæmatopœsis. The thoroughness with which the various aspects of the question are discussed is revealed by the extent of the bibliography which amounts to almost 700 references, the vast majority of which date from 1930 .

The value of such a survey by two men who have themselves contributed so much to the elucidation of the anæmias cannot be exaggerated. The balanced judgment in the evaluation of opposing views and the lucid exposition of their own opinions make the whole work a pleasure to read.

\section{RECENT ADVANCES IN}

\section{ALLERGY.}

(Third Edition).

By G. W. Bray, M.B. J. \& A. Churchill, Ltd. 1936. Price 15/-.

The medical profession is under a debt of gratitude to Dr. Bray for collecting and submitting to a critical analysis all the work done on the subject of allergy which has assumed within recent years such an important rôle in the pathogenesis of disease. Such a task of course could only be satisfactorily performed by one who has himself devoted much time to the elucidation of the various problems involved, and throughout the text there is abundant evidence of Dr. Bray's own and important contributions. That his labours are appreciated by his colleagues is surely revealed by the fact that the present edition is the third since the first appearance of the work in 1931.

Dr. Bray discusses the whole field of the subject-the nature of the phenomenon, its experimental production, the clinical manifestations which are met with in man, the technique to be employed for the identification of the particular exciting factor (the discovery of which alone can permit of the appropriate treatment) and the way in which any therapeutic measures should be carried out.

\section{THE}

\section{CLINICAL USE OF DIGITALIS.}

By Drew Luten, M.D. London. Bailliere,

Tindall and Cox. 1936. 16/-.

Digitalis ranks in therapeutic importance with opium, iron and cod liver oil and deserves the careful attention of practising physicians. Since 1785, when Withering published his classical work on the foxglove, an almost unmanageable volume of literature has accumulated on this subject. Dr. Luten has taken a comprehensive but critical view of these writings and has presented the conclusions regarding digitalis therapy in the light of his own clinical observations. In the space of some 200 pages the author handles the subject in a fashion which cannot fail to excite interest and admiration. Throughout, the treatment is logical and concise without being dogmatic. Pharmacologists may regret the exclusion of the more recent work on the digitalis glycosides but from the clinician's point of view this is not a serious omission. 